\title{
Heavy Physical Exertion Effect on Functional Indices of Cardiovascular System Under Sharp Reduction of High-Qualification Woman Gymnasts' Weight During Competition Period
}

\author{
Dorontsev A.V. \\ Astrakhan State Medical University \\ Astrakhan, Russia \\ aleksandr.doroncev@ rambler.ru
}

\author{
Svetlichkina A.A. \\ Astrakhan State Medical University \\ Astrakhan, Russia \\ doronceva@ rambler.ru
}

\author{
Zinchuk N.A. \\ Astrakhan State University \\ Astrakhan, Russia \\ niva-zinchuk@mail.ru
}

\begin{abstract}
A study on pronounced changes in haemodynamic indices under heavy physical exertion against short-period weight reduction was carried out among high-qualification woman gymnasts. As a rule, sharp weight reduction was observed among some of the gymnasts during the competition period, which allowed to detect significant reduction in reserve indices of the cardiovascular system, as well as the risk of pathological changes genesis under heavy physical exertion. According to the study, significant changes of the high-qualification gymnasts' cardiovascular system functional indices were observed when they lost 3-4 $\mathrm{kg}$ in weight several days prior to the competitions, with their own weight of $45-50 \mathrm{~kg}$; when the weight reduction was softer - up to $1.5 \mathrm{~kg}$ per month - there were no pronounced changes in haemodynamic indices. The obtained results suggest removal of weight reduction stress methods, posing risks of organic changes of the cardiovascular system under heavy physical exertion, from rhythmic gymnastics training exercises.
\end{abstract}

Keywords-cardiovascular system; rhythmic gymnastics; exertion; immediate weight reduction.

\section{INTRODUCTION}

Dietary restriction and low-calorie diets, observed in different sports for efficient weight reduction, lead to major losses of water, electrolytes, minerals, glycogen and other non-fat tissues with minimum loss of fat [2]. Some athletes tend to use loop diuretics to reduce their weight immediately during the competition period [4]. Extreme physical exertion against body dehydration may lead to myocardium overexertion and pose significant risks for health [3, 5]. Experts say that the dynamism, typical for many sports, together with high emotional strain demands higher endurance of the locomotor and cardio-respiratory systems and requires extreme mobilization of all functional systems of the organism $[2,5,6,7]$. All this leads to depletion of energy resources and reduction of athletes' compensation abilities [6]. In some cases, it leads to development of cardiovascular diseases [8]. Taking into consideration the relevance of the issue, we conducted a study on the effect of high-qualification woman gymnasts' weight immediate reduction during the competition period.

The study objective is to examine the effect of competition-level exertion on the cardiovascular system of high-qualification woman gymnasts against sharp reduction of their weight.

\section{MATERIALS AND METHODS}

The study involved 19 young women at the age of 15-17 with the sports qualification "Master of Sports". Two groups were formed from the overall number of the athletes: the first group included eight gymnasts that applied the method of forced weight reduction during the competition period $\left(n^{1}-8\right)$, while the second group of 11 athletes $\left(n^{2}-11\right)$ adjusted their weight on a scheduled basis during the preparatory season. Then the clinical data, electrocardiography and echocardioscopy indices were analyzed. The study was carried out with the use of the following means: 3-channel electrocardiograph Cardiovit AT-101 (Schiller, Switzerland), Holter ECG recorder Microvit MT-101 and analysis program MT-200 (Schiller, Switzerland), spreadsheet program Microsoft Excel 2007 with XLSTAT-Pro macro-addin (Microsoft, USA) and statistical analysis package Statistical0 (StatSoftInc., USA). The study was conducted at the Children $\&$ Youth Sports School of the Olympic Reserve No.5 named after L.A. Tikhomirova and the Astrakhan State Medical University in 2017-2019. The statistical significance was assessed with Student's test. Differences were considered significant if $p<0.05$. The correlation analysis was conducted with the use of the Pearson correlation coefficient.

\section{RESULTS AND DISCUSSION}

All the examined athletes subjectively felt healthy, there were no health complaints, no abnormality was detected in the lungs auscultatory condition, no pathological accentuation or cardiac murmur above the heart region was heard. 
The analysis of electrocardiogram indices of the gymnasts $\left(\mathrm{n}^{1}-8\right)$ under the weight reduction of $3 \pm 0.5 \mathrm{~kg} \mathrm{3}-5$ days prior to the competitions identified the following borderline changes in haemodynamic indices of the cardiovascular system. $37.5 \%$ of the gymnasts had sinus tachycardia, 25\% had sinus tachyarrhythmia, which are indicators of the cardiovascular system detraining and, in our opinion, are connected with electrolyte imbalance, occurring against immediate weight reduction. $12.5 \%$ of the examined athletes had single supraventricular extrasystole, intensifying during ECG rerecording after a functional test on a stationary bicycle (with the power up to $200 \mathrm{~W}$ ). This athlete needed follow-up examination, viz. daily ECG monitoring, and was excluded from nearest competitions. In 4 cases, the electrocardiogram registered nonspecific changes in myocardium repolarization processes, indicating possible electrolyte deficiency (hypokalemia). Besides, $25 \%$ of the athletes had the syndrome of early ventricular repolarization as a result of changes in the autonomic nervous system with a prevailing effect of the vagus nerve. It was proved by physical exertion tests, during which the syndrome signs disappeared; $50 \%$ had the firstdegree atrioventricular block (PQ-0.21s interval). It is considered an indicator of the gymnasts cardiovascular system good training, belonging to the group $\left(n^{2}=11\right)$ who did not applied the methods of forced weight reduction; no borderline changes of cardiovascular indices were recorded.

TABLE I. HAEMODYNAMIC INDICES OF MASTERS OF SPORTS IN RHYTHMIC GYMNASTICS

\begin{tabular}{|l|c|c|c|c|}
\hline \multicolumn{1}{|c|}{ Indices } & $\begin{array}{c}\text { Group 1 } \\
\left(\mathrm{n}^{1}-8\right)\end{array}$ & $\begin{array}{l}\text { Group 2 } \\
\left(\mathrm{n}^{2}-11\right)\end{array}$ & $\begin{array}{c}\text { Group 1 } \\
\left(\mathrm{n}^{1}-8\right)\end{array}$ & $\begin{array}{l}\text { Group 2 } \\
\left(\mathrm{n}^{2}-11\right)\end{array}$ \\
\cline { 2 - 5 } & $\begin{array}{c}\text { During the } \\
\text { preparatory } \\
\text { season }\end{array}$ & $\begin{array}{l}\text { During the } \\
\text { preparatory } \\
\text { season }\end{array}$ & $\begin{array}{c}\text { During the } \\
\text { competition } \\
\text { period }\end{array}$ & $\begin{array}{l}\text { During the } \\
\text { competitio } \\
\mathrm{n} \text { period }\end{array}$ \\
\hline $\begin{array}{l}\text { Systolic blood } \\
\text { pressure at rest, } \\
\text { mmHg }\end{array}$ & $138 \pm 9.7$ & $140 \pm 8.4$ & $140 \pm 8.8$ & $134 \pm 7.7$ \\
\hline $\begin{array}{l}\text { Diastolic blood } \\
\text { pressure at rest, } \\
\text { mmHg }\end{array}$ & $88.1 \pm 5.4$ & $90.7 \pm 5.7$ & $90.2 \pm 5.9$ & $87.3 \pm 4.3$ \\
\hline $\begin{array}{l}\text { Systolic blood } \\
\text { pressure during the } \\
\text { early recovery } \\
\text { period, mmHg }\end{array}$ & $165.8 \pm 11.2$ & $161.0 \pm 10.3$ & $160.3 \pm 10.1$ & $149.1 \pm 9.7$ \\
\hline $\begin{array}{l}\text { Diastolic blood } \\
\text { pressure during the } \\
\text { early recovery } \\
\text { period, mmHg }\end{array}$ & $108.4 \pm 10.5$ & $109.2 \pm 8.7$ & $105.7 \pm 10.7$ & $95.7 \pm 8.7$ \\
\hline $\begin{array}{l}\text { Heart rate at rest, } \\
\text { BPM }\end{array}$ & $89.3 \pm 9.0$ & $88.1 \pm 8.7 *$ & $85.7 \pm 7.3$ & $82.2 \pm 5.4$ \\
\hline $\begin{array}{l}\text { Heart rate during the } \\
\text { early recovery } \\
\text { period, BPM }\end{array}$ & $158.2 \pm 9.2$ & $162.1 \pm 10.0$ & $160.4 \pm 9.7$ & $148.7 \pm 10.5$ \\
\hline \multicolumn{4}{|l|}{ Note: $* 00.05$ is given in comparison with group 1 } & \\
\hline
\end{tabular}

The autocorrelation function coefficients, obtained during further mathematical processing, allowed to identify a pronounced and statistically significant dependence of sharp reduction of high-qualification woman gymnasts' weight and detection of pre-pathological changes of haemodynamic indices $(r=0.495 ; \mathrm{p}<0.05)$.

\section{CONCLUSIONS}

Therefore, the conducted study shows that during the immediate weight reduction period, high-qualification woman gymnasts, examined with the electrocardiogram, often appear to have sinus tachycardia, sinus tachyarrhythmia, supraventricular extrasystole and abnormalities in processes of left ventricle myocardium repolarization, associated with excessive dehydration of the organism and fluid-andelectrolyte disturbance. These changes indicate dehydration and require athletes' exclusion from training classes and competitions. In some cases, it is necessary to conduct metabolic therapy to recover functional reserves of the cardiovascular system.

All the above stated allows to draw a conclusion that the forced weight reduction may lead to significant changes in haemodynamic indices and development of organic changes in the cardiovascular system. Therefore, an expedient choice of training means for weight regulation and regular control over athletes' cardiovascular system during training classes and competition periods will allow to significantly reduce the risk of pathological changes development in the cardiovascular system, caused by extreme physical exertion.

\section{References}

[1] Batyrev, E.M., Dorontsev, A.V. Assessment of the preventive health care skills development degree in medical university students by means of physical training and sports. Scientific Notes of the Lesgaft University. 2009, No. 12 (58), pp. 13-17.

[2] Kazilov M.M., Podlivaev, B.A. Issues of weight reduction and performance improvement in wrestling. Bulletin of MAMI Moscow Polytechnic University. 2014, vol. 5, No.2 (20), pp. 155-162.

[3] Legotkin, A.N., Lopatin, A.B. Athletes' ontogenesis and physical exertion. International scientific \& research journal. Success of Modern Science and Education. 2016, vol. 1, No.12, pp.122-125.

[4] Polevaya, N.V. Methods of athletes' weight balanced reduction in combat sports. Tomsk State University Journal. 2009, No.322, pp.218-222.

[5] Svetlichkina, A.A., Dorontsev, A.V. Phenomenon of short PQ interval as a risk factor in physical training and sports. Scientific Notes of the Lesgaft University. 2016, No.9 (139). pp. 171-175.

[6] Svetlichkina, A.A., Kozlyatnikov, O.A. Exertion intensity planning on the basis of Astrakhan State Medical University high-qualification athletes and students ECG examination. Scientific Notes of the Lesgaft University. 2016, No.3 (133), pp. 214-217.

[7] Chichkova, M.A. Current issues of patients with cardiac diseases diagnostics and treatment in Astrakhan region at modern stage. Astrakhan Medical Journal. 2008, No.2, pp. 5-10.

[8] Chichkova M.A., Svetlichkina A.A., Dorontsev A.V. Comparative characteristic of cardiovascular system state among people going in for competitive and health-improving body-building. The Russian Journal of Physical Education and Sport. 2018, vol. 13, No 1, pp. 148-152. DOI: 10/14526/01_2018_300 